\title{
Thermomechanical Analysis of a Bulk of Electrically Conductive Adhesive
}

\author{
David Bušek $^{1)}$, Ivana Pilarčíková ${ }^{2)}$, Pavel Mach ${ }^{3)}$ \\ Department of Electrotechnology, Faculty of Electrical Engineering, \\ Technická 2, 16627 Prague, Czech Republic, Phone: +420 224352355 \\ busekd1@fel.cvut.cz',pilarcik@fel.cvut.cz'mach@fel.cvut.cz ${ }^{3}$
}

\begin{abstract}
Mechanical properties of isotropically conductive adhesives depend not just on the internal structure and composition (amount and type of binder and filler) of the adhesive, but also on chemical processes that are influenced by curing. Thermomechanical analysis allows to distinguish the point when the adhesive is fully cured, it may reveal a difference in mechanical properties after different modifications of the adhesive, it may give a clue to better thermal processing of the adhesive while curing. Thermal analysis of totally nine types of adhesive modifications was performed, particularly the influence of carbon nanotubes addition, silver nanoparticles and colloidal silver was observed. In our tests, both one-component and two-component adhesives were used. The overview of tested adhesives and their modifications is described in table 1.
\end{abstract}

\section{INTRODUCTION}

The use of electrically conductive adhesives (ECAs), is one of many methods of creating conductive connections in an electronic circuit. Most used nowadays are lead free solders, but applications exists, where soldering is not suitable or possible, particularly when organic substrates, like liquid crystals are present. As ECAs are still worse in their electrical and mechanical properties when compared to solders, several studies with an aim to improve and test their characteristics are ongoing. Every conductive adhesive consists of conductive filler and a matrix that largely determines their mechanical stability and resistance to atmospheric conditions. As indicated, this paper is focused on an evaluation of mechanical properties of bulk adhesives. The composition of ECA was modified in order to change mechanical properties of the bulk material; the resulting composition was evaluated using Thermomechanical analysis (TMA).

\section{What is Thermal ANALYSIS?}

Thermal Analysis (TA) is the collective name for different sub-types of thermal analysis. These are thermomechanical analysis, coefficient of thermal expansion, dynamic mechanical analysis, and differential scanning calorimetry.

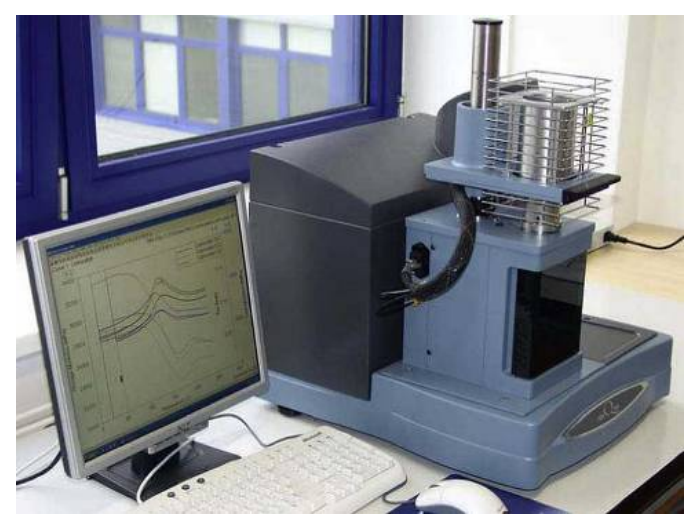

Fig. 1. TA Instrument for DMA analysis

Dynamic mechanical analysis (DMA) is considered one of the most accurate techniques for glass transition temperature $\left(\mathrm{T}_{\mathrm{g}}\right)$ measurement. DMA is a technique in which the deformation of a sample under oscillatory load is measured as a function of temperature. The method is capable of characterization and interpretation of the mechanical behavior of the observed sample. In short, it consists of the application of oscillating force to a sample and 
observation of the material response to that force [1]. This method is particularly suitable for observing properties of polymer materials. One of the main advantages is the suitability to quickly determine polymer properties as a function of frequency, temperature or time with the use of only a very small material sample.

Differential scanning calorimetry, DSC, is also a thermo-analytical technique in which the difference in the amount of heat required to increase the temperature of a sample and reference are measured as a function of temperature. The sample and the reference are maintained at the same temperature during the experiment. The DSC analysis uses a program with linear increase of the sample holder's temperature as a function of time. The reference sample should have a well-defined heat capacity over the range of temperatures to be scanned.

The main application of DSC is in studying phase transitions, particularly glass transitions, melting transitions and exothermic decompositions. All of these phase changes are accompanied by energy or heat capacity changes that can be detected using very accurate DSC measuring device. The principle of the measurement is not a newcomer; first documented commercial application was introduced in 1963.

The apparatus for DSC measurement measures energy directly and allows precise measurement of heat capacity [2].

\section{SAMPLES}

\subsection{Sample preparation}

In order to measure mechanical properties of the bulk adhesive, samples with specific design had to be manufactured. For dynamic mechanical analysis, scantlings of the following dimensions $(15 \times 5 \times 1,5) \mathrm{mm}$ were prepared.

As all of the adhesives have high adhesion to many materials, silicon forms of above mentioned dimensions were created, then filled with chosen adhesive modification and cured. The volume in a sample of above mentioned size is larger than is commonly used in a manufacturing process, where the adhesive is used as a joint; therefore it was necessary to set the curing time experimentally. Flat profile temperature oven was used for the curing process.

\subsection{Issues connected to sample preparation}

Cured samples were additionally grinded on a sand-paper in order to get as homogenously sized samples as possible. One of the factors that can influence measured parameters was the nonhomogenity caused by bubbles dispersed in the adhesive. Picture below shows different adhesive types and their modifications. It is easily noticeable, that not only bubbles create the non-homogenities, but also the added carbon is hard to disperse.
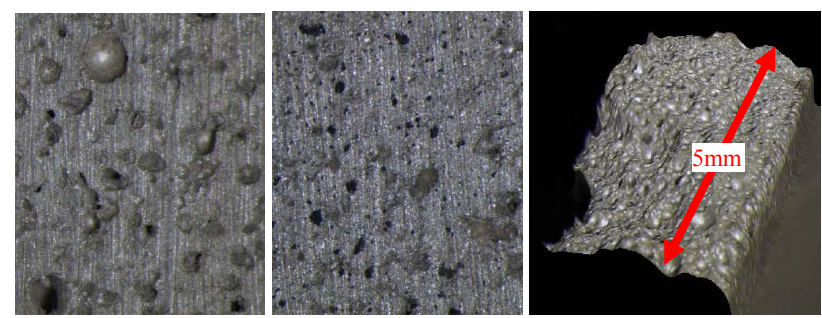

Fig. 2. Measured sample surface after magnification, $\mathrm{AX} 12 \mathrm{MN}$ on the left, AX20 with carbon nanotubes in the middle, broken AX15S sample on the right.

\section{Measuring}

There are several probes used for TMA analysis. These are expansion/ dilatometric / penetration / three point bending / hemispheric / tensile and threads measurement probes [3].

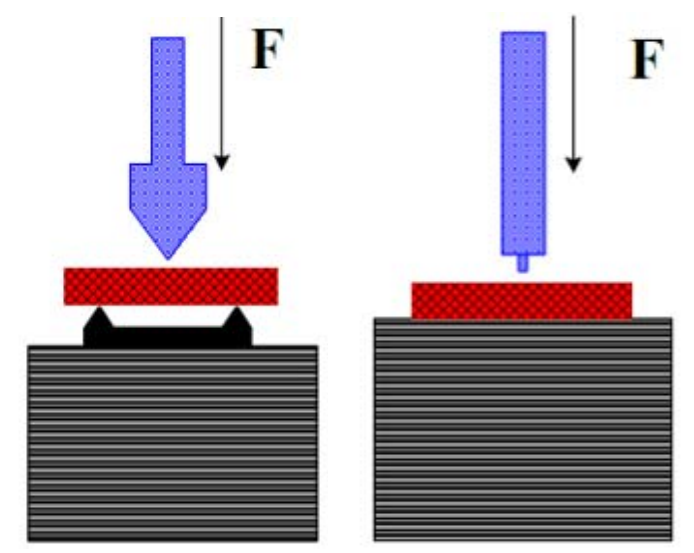

Fig. 3. Some of the testing probes for DMA analysis

Initially, the use of three point bending probe was planned (Fig.3, left), but as the samples were too stiff, the penetration probe was used for DMA analysis (Fig. 3, right) 


\section{RESULTS}

\subsection{Sample marking}

\begin{tabular}{|c|c|}
\hline \multicolumn{2}{|c|}{ Sample marking } \\
\hline Marking & Composition \\
\hline 1A & AX20+CNT \\
\hline 1B & AX20+CNT 0,67\% \\
\hline 2A & AX20+nAg \\
\hline $3 A$ & AX20+kAg \\
\hline $3 B$ & AX20+kAg 10\% \\
\hline $4 A$ & AX70 MN+CNT \\
\hline 5A & AX70 MN+kAg \\
\hline 6A & AX 15S \\
\hline 7A & AX 12MN \\
\hline
\end{tabular}

Tab. 1. Samples used for measurement

nAg... Silver nanoparticles (diameter 100-150 nm), $2,5 \%$ weight addition

CNT... carbon nanotubes, multiwalled, approx: 20$50 \mathrm{~nm} \times 5-20 \mu \mathrm{m}, 0,3 \%$ weight addition

$\mathrm{kAg}$... colloidal dispersion of pure silver, $2,5 \%$ weight addition

AX20...epoxy-phenolic based conductive adhesive with silver filler $75 \%$ wt

AX70 MN... epoxy-phenolic based conductive adhesive with silver filler $70 \%$ wt

\subsection{DSC analysis}

DSC analysis using apparatus SDT Q600 was conducted on all adhesive types.

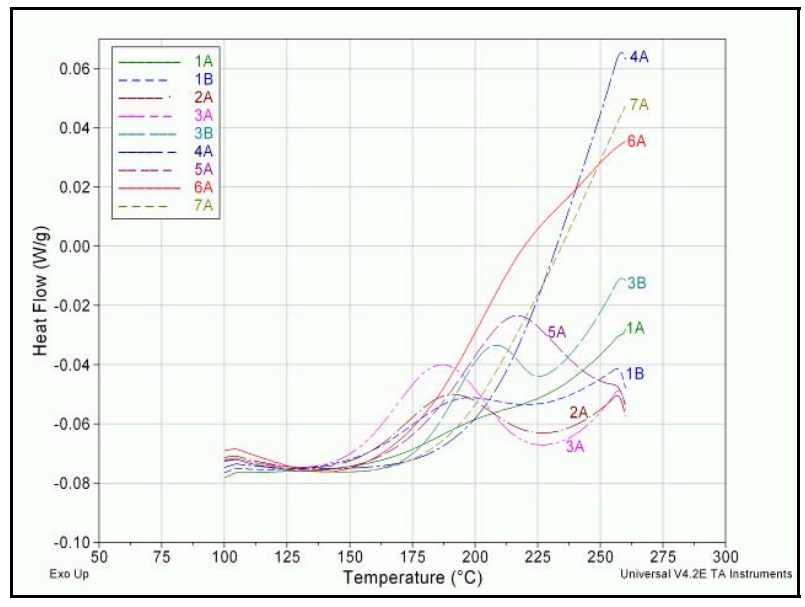

Fig. 4. Heat flow diagram while DSC analysis
DSC revealed that the adhesives were not fully cured, peaks in figure above show their curing temperature, adhesives based on AX20 exhibit lower curing temperature than $\mathrm{AX} 70 \mathrm{MN}$ but even for $\mathrm{AX} 20$, the temperature is $185^{\circ} \mathrm{C}$ what is higher than the producer states in the technical datasheet $\left(150^{\circ} \mathrm{C}\right.$ for both adhesives). The curing temperature for $\mathrm{AX} 70 \mathrm{MN}$ type is even higher, $215^{\circ} \mathrm{C}$. The reason why these adhesives are not fully cured after prescript time may be due to the manufacturer effort to prolong the function time of the adhesive - firstly, setting up and curing will occur, even then, the ageing starts. For some of the lines, a peak is missing - that means that either the adhesive was fully cured or over-cured, or that the curing temperature cannot be revealed using this type of measuring method.

\subsection{DMA analysis}

DMA analysis using apparatus TMA Q400EM and penetration probe was conducted. It was not possible to use the three point bending probe due to the stiffness of most of the samples. The temperature during this measurement was increasing with a ramp of $5^{\circ} \mathrm{C}$ up to $140^{\circ} \mathrm{C}$ while modulate force $+/-0,3 \mathrm{~N}$ at $1 \mathrm{~Hz}$ was applied to the sample. The DMA analysis proved to be most suitable for glass transition temperature measurement. Over DSC, the DMA analysis is capable of showing the influence of proper curing (see table 2 below) on mechanical stability of the sample. The glass transition temperature was estimated from the second heating Tan. delta temperature dependence.

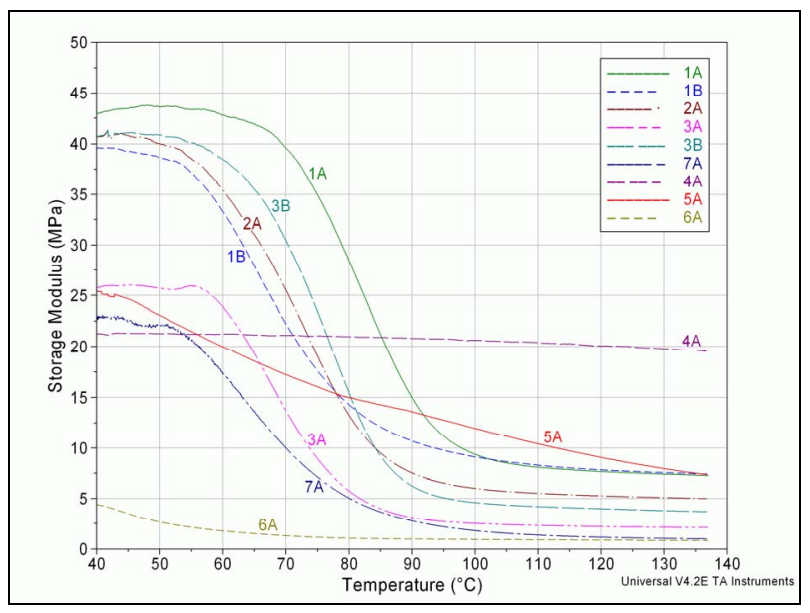

Fig. 5. Storage modulus measurement 
The DMA analysis proved to be most suitable for glass transition temperature measurement. Over DSC, the DMA analysis is capable of showing the influence of proper curing.

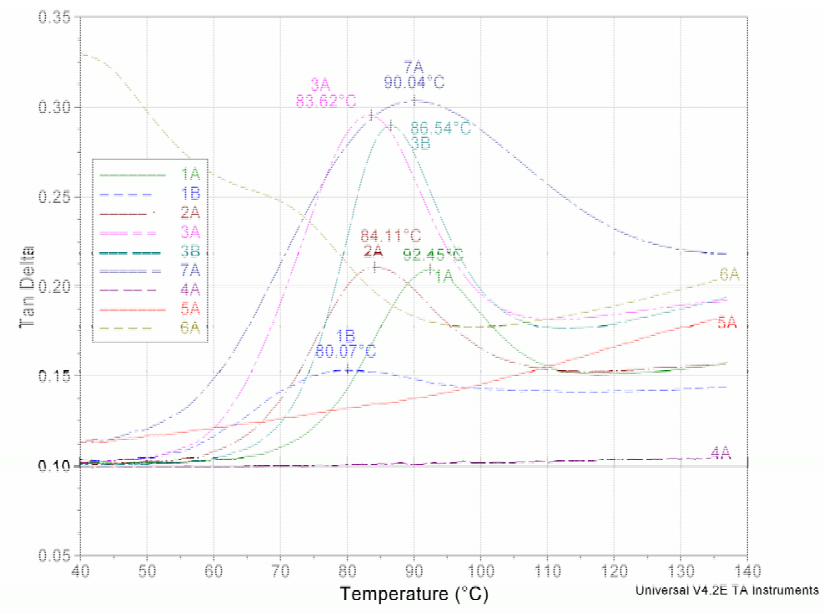

Fig. 6. Tg estimation on fully cured samples $\left(2^{\text {nd }}\right.$ heating $)$

Glass transition temperature increase after second heating (proper curing)

\begin{tabular}{|c|r|r|r|}
\hline Sample & $\begin{array}{r}\mathrm{T}_{\mathrm{g}} \\
1^{\text {st }} \text { heating }\end{array}$ & $\begin{array}{r}\mathrm{T}_{\mathrm{g}} \\
2^{\text {nd }} \text { heating }\end{array}$ & $\begin{array}{c}\% \\
\text { increase }\end{array}$ \\
\hline 1A & 84,74 & 92,45 & 9,10 \\
\hline 1B & 74,05 & 80,07 & 8,13 \\
\hline 2A & 77,14 & 84,11 & 9,04 \\
\hline $3 \mathrm{~A}$ & 71,99 & 83,62 & 16,16 \\
\hline 3B & 78,5 & 86,54 & 10,24 \\
\hline 4A & $\mathrm{N} / \mathrm{A}$ & $\mathrm{N} / \mathrm{A}$ & $\mathrm{N} / \mathrm{A}$ \\
\hline 5A & $\mathrm{N} / \mathrm{A}$ & $\mathrm{N} / \mathrm{A}$ & $\mathrm{N} / \mathrm{A}$ \\
\hline 6A & $\mathrm{N} / \mathrm{A}$ & $\mathrm{N} / \mathrm{A}$ & $\mathrm{N} / \mathrm{A}$ \\
\hline 7A & 81,33 & 90,04 & 10,71 \\
\hline
\end{tabular}

Tab. 2. Glass temperature change after proper curing

Table 2 summarizes the influence and importance of proper curing. Even though the samples seemed to be sufficiently cured, the DMA analysis revealed significant glass temperature increase after additional heat treatment. Figure 7 shows differences caused by vacuum curing process. The glass transition decreased after vacuum curing and therefore this method is not advisable.

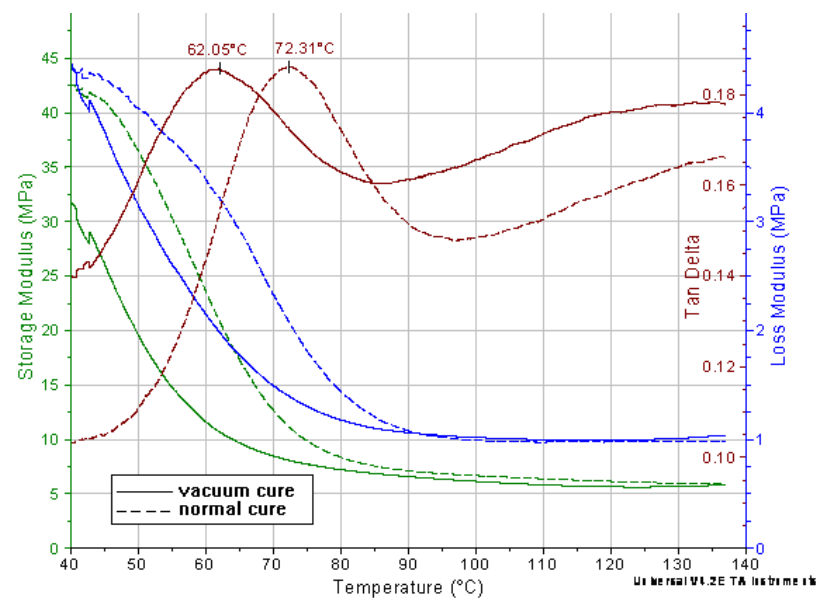

Fig. 7. Comparison between vacuum and standard curing process

\section{Conclusion}

A significant relation between DSC and DMA analysis can be found. In contrast to DSC, dynamic analysis, DMA, is able to show differences between adhesive modifications even after proper curing (during second heating). From the thermomechanical-analysis point of view, mechanical properties of the A1 sample (with $0,3 \%$ weight carbon nanotube addition) exhibits the best properties. The dynamic analysis showed good mechanical properties (Fig.5) and the highest glass transition temperature (Fig.6). Other mechanical tests are necessary to confirm generally better properties with carbon nanotube addition.

\section{ACKNOWLEDGEMENT}

This research was supported by grant: Czech Republic - MSM No.6840770021 - Diagnostic of Materials

\section{REFERENCES}

[1] R.Polanský ,V.Mentlík,P.Prosr, J.Sušír, "Influence of thermal treatment on the glass transition temperature of thermosetting epoxy laminate", Polymer Testing 28(2009), pp428-436

[2] Wunderlich, B. (1990) “Thermal Analysis" New York: Academic Press. pp. 137-140

[3] R.Polanský, "Teoretické a praktické aspekty termomechanické analýzy", Elektrorevue 15/2008, pp15-1-15-1 